\title{
SIRT1 inhibits apoptosis in in vivo and in vitro models of spinal cord injury via microRNA-494
}

\author{
XIAOBING YU, SHUO ZHANG, DEWEI ZHAO, XIUZHI ZHANG, CHONGJUN XIA, \\ TIENAN WANG, MENG ZHANG, TAO LIU, WEI HUANG and BAOLIN WU
}

Department of Orthopaedics, Zhongshan Hospital of Dalian University, Dalian, Liaoning 116001, P.R. China

Received December 10, 2017; Accepted January 21, 2019

DOI: $10.3892 /$ ijmm.2019.4106

\begin{abstract}
The aim of the present study was to investigate the function and mechanism of sirtuin 1 (SIRT1) in spinal cord injury (SCI). Reverse transcription-quantitative polymerase chain reaction was used to measure the expression levels of microRNA (miR)-494. MTT assay, lactate dehydrogenase activity assay and flow cytometry were used to analyze the effects of miR-494 on cell growth and apoptosis in a model of SCI. The present study demonstrated that SIRT1 expression was reduced; whereas miR-494 expression was increased in a rat model of SCI. Overexpression of miR-494 suppressed the protein expression levels of SIRT1, and induced p53 protein expression. Conversely, knockdown of miR-494 induced SIRT1 protein expression in an in vitro model of SCI. Furthermore, overexpression of miR-494 promoted cell apoptosis and decreased cell growth in an in vitro model of SCI; however, miR-494 knockdown enhanced cell growth and inhibited cell apoptosis. Administration of a SIRT1 agonist reduced the effects of miR-494 overexpression on cell apoptosis in an SCI model, whereas treatment with a p53 agonist reduced the effects of miR-494 knockdown on cell apoptosis in an SCI model. Together, these findings suggested that SIRT1 may inhibit apoptosis of SCI in vivo and in vitro through the p53 signaling pathway, whereas miR-494 suppressed SIRT1 and induced apoptosis.
\end{abstract}

\section{Introduction}

Spinal cord injury (SCI) leads to severe motor and sensory dysfunction, and severely affects patients both mentally and physically (1). SCI is one of the major causes of disability (2), the clinical treatment of which is complex. At present, there is no available interventional treatment that is completely

Correspondence to: Dr Xiaobing Yu, Department of Orthopaedics, Zhongshan Hospital of Dalian University, 6 Jiefang Street, Dalian, Liaoning 116001, P.R. China

E-mail: dldxyxb@163.com

Key words: sirtuin 1, spinal cord injury, microRNA-494, p53, apoptosis effective for SCI (3). The pathophysiological process of SCI includes primary and secondary injuries (4). Secondary injury generally occurs within several hours, days or weeks after the primary injury (4). It comprises post-traumatic inflammatory response, neuronal apoptosis and necrosis, local tissue microcirculatory ischemia and hypoxia, oxidative stress response, and the excessive production of peroxide and reactive oxygen species (2). Secondary injury further damages the spinal cord and can lead to akinesthesia (5); however, the mechanism underlying secondary injury is currently unclear. It is known that secondary injury induces recruitment of a large number of inflammatory cells at the early stage, which is accompanied by a strong inflammatory response, and neuronal necrosis and apoptosis (5).

Silent information regulator 2 (Sir2)-associated enzymes are highly conserved $\mathrm{NAD}^{+}$-dependent histone deacetylases (6). There are seven Sir2 homologous genes in the human body, namely, sirtuin (SIRT)1-7 (6). SIRT1 has been the focus of much research in recent years. The SIRT1 protein has been revealed to exert anti-inflammatory and antioxidative effects, and can alleviate cell injury. In addition, SIRT1 is able to markedly reduce the amyloid- $\beta$ protein-induced nuclear factor $(\mathrm{NF})-\kappa \mathrm{B}$ pathway and decrease the production of inflammatory factors (7). It can also suppress inflammatory response-induced injury to protocortical neurons. A possible underlying mechanism for these effects is that SIRT1 acts on the NF- $\kappa \mathrm{B}$ subunit, RelA/p65, through deacetylation; therefore, SIRT1 can participate in regulating $\mathrm{NF}-\kappa \mathrm{B}$ active genes. In particular, SIRT1 can reduce the binding of $\mathrm{NF}-\kappa \mathrm{B}$ with intranuclear inflammatory genes, and can thus reduce the production of inflammatory factors, such as TNF- $\alpha$ and IL-1 $\beta$ (8).

MicroRNAs (miRNAs/miRs) are gene expression regulatory factors, which were discovered $>20$ years ago (3). Expression of numerous miRNAs is altered in response to SCI. It has previously been reported that miRNAs participate in the regulation of post-SCI gene expression; such gene expression alterations are closely associated with certain pathological processes (3), including ischemia and swelling of the spinal cord, the inflammatory response and neuronal necrosis. Molecular biology has developed rapidly; as a result, research regarding miRNA has attracted increasing attention. It has previously been indicated that miRNAs serve vital regulatory roles in spinal development, spinal plasticity, 
and post-SCI pathogenesis and developmental processes (9). Therefore, some miRNAs may be considered effective targets for post-SCI therapeutic intervention, and investigating the function and role of miRNAs in the pathological development of SCI may aid understanding of the pathogenesis of secondary SCI. Furthermore, research into miRNAs may provide novel therapeutic targets and intervention strategies for SCI treatment and rehabilitation (1). The present study aimed to investigate the function and mechanism of SIRT1 in SCI. In the present study, an in vivo model was used to study primary SCI injury, and an in vitro model was used to study secondary SCI injury

\section{Materials and methods}

Experimental animals and establishment of an animal model. The present study was approved by the Scientific Review Committee and the Institutional Review board of Dalian University (Dalian, China). Healthy male Sprague-Dawley rats (weight, 200-250 g; age, 9-11 weeks, n=12) were obtained from the Animal Center of Dalian University. All rats were maintained under a $12-\mathrm{h}$ dark/light cycle at $22-24^{\circ} \mathrm{C}$ (relative humidity 55-60\%), and received ad libitum access to a standard laboratory diet and water. The rats were randomly assigned into the following two groups: Control group $(n=6)$ and SCI model group $(n=6)$. All rats in the SCI model group were anesthetized with an intraperitoneal (i.p.) injection of $30 \mathrm{mg} / \mathrm{kg}$ pentobarbital sodium, after which T8-T9 spinous processes and lamina were uncovered, and paraspinal muscles were stripped. Subsequently, the T8 and T9 spinous processes were clamped with forceps and lamina was removed to expose the dura mater. The underlying cord was exposed to contusion injury without disrupting the dura (10). All rats in the control group were anesthetized with an i.p. injection of $30 \mathrm{mg} / \mathrm{kg}$ pentobarbital sodium; however, they did not undergo SCI. A total of 1 day after induction of the SCI model, rats were anesthetized with an i.p. injection of $30 \mathrm{mg} / \mathrm{kg}$ pentobarbital sodium and were sacrificed by decapitation. Subsequently, spinal cord samples were collected and stored at $-80^{\circ} \mathrm{C}$.

Basso, Beattie, Bresnahan (BBB) score and water content analysis. The BBB score of the rats was determined after 4 min in an open field (1), and was scored between 0 (no observable hind-limb movements) and 21 (normal locomotion). For water content analysis of the spinal cord, spinal cord samples were weighed, dried at $80^{\circ} \mathrm{C}$ for $24 \mathrm{~h}$ and were then weighed again. The following formula was used to calculate the spinal cord water content: [(Wet weight-dry weight)/wet weight] x100\%.

Hematoxylin and eosin staining. Spinal cord samples were fixed with $4 \%$ paraformaldehyde for $48 \mathrm{~h}$ at room temperature, embedded in paraffin and cut into $10-\mu \mathrm{m}$ sections. The tissue samples were then stained with hematoxylin and eosin for $10 \mathrm{~min}$, and examined under a fluorescence microscope (BX53; Olympus Corporation, Tokyo, Japan).

Reverse transcription-quantitative polymerase chain reaction $(R T-q P C R)$. Total RNA was isolated from spinal cord tissues and transfected cells using TRIzol ${ }^{\circledR}$ reagent (Invitrogen; Thermo Fisher Scientific, Inc., Waltham, MA,
USA), according to the manufacturer's protocol. cDNA was obtained using the ImProm-II Reverse Transcription system (Promega Corporation, Madison, WI, USA), according to manufacturer's protocol. RT-qPCR was performed with SYBR Green PCR Mater Mix (Applied Biosystems; Thermo Fisher Scientific, Inc.) on an ABI 7900HT fast real-time PCR system (Applied Biosystems; Thermo Fisher Scientific, Inc.). The primer sequences were as follows: SIRT1, forward 5'-TCA GTGTCATGGTTCCTTTGC-3', reverse 5'-AATCTGCTC CTTTGCCACTCT-3'; GAPDH, forward 5'-CCCCTGGCC AAGGTCATCCA-3', reverse 5'-CGGAAGCCATGCCAG TGAG-3'; miR-494, forward 5'-CATAGCCCGTGAAACATA CACG-3', reverse 5'-GTGCAGGGTCCGAGGT-3'; and U6 forward 5'-CGCTTCGGCAGCACATATACTA-3' and reverse 5'-GCGAGCACAGAATTAATACGAC-3'. The qPCR thermocycling conditions were as follows: $95^{\circ} \mathrm{C}$ for $10 \mathrm{~min}$; followed by 40 cycles at $95^{\circ} \mathrm{C}$ for $25 \mathrm{sec}, 60^{\circ} \mathrm{C}$ for $25 \mathrm{sec}$ and $72^{\circ} \mathrm{C}$ for $25 \mathrm{sec}$, and a final extension step at $4^{\circ} \mathrm{C}$ for $10 \mathrm{~min}$. Relative expression levels were calculated using the $2^{-\Delta \Delta \mathrm{Cq}}$ method (11).

Gene microarray hybridization. Total RNA (500 ng) was labeled with Cyanine-5-CTP (cat. no. NEL474001EA; PerkinElmer, Inc., Waltham, MA, USA) and hybridized using the SurePrint G3 Mouse Whole Genome GE Microarray G4852A platform (cat. no. G4851A; Agilent Technologies, Inc., Santa Clara, CA, USA) with an equimolar concentration of cyanine-3-cTP-labelled universal rat reference (Stratagene; Agilent Technologies, Inc.). Images were analyzed using Agilent Feature Extraction 10.7.3.1 software (Agilent Technologies, Inc.).

Cell line, and cell culture and transfection. PC12 cells were used to study SCI in vitro, as previously reported (12-14). PC12 cells were purchased from the American Type Culture Collection (Manassas, VA, USA) and were maintained in Dulbecco's modified Eagle's medium (DMEM; Gibco; Thermo Fisher Scientific, Inc.) supplemented with $10 \%$ fetal bovine serum (FBS; Gibco; Thermo Fisher Scientific, Inc.) in a humidified atmosphere containing $5 \% \mathrm{CO}_{2}$ at $37^{\circ} \mathrm{C}$. miR-494 mimics (5'-UGAAACAUACACGGGAAACCUC-3'), anti-miR-494 mimics (5'-GGUUUCCCGUGUAUGUUU CAUU-3') and a negative control (5'-UUCUCCGAACGU GUCACGU-3') were obtained from Shanghai GenePharma Co., Ltd. (Shanghai, China). Cell transfection $\left(1 \times 10^{6}\right.$ cells $\left./ \mathrm{ml}\right)$ was performed using Lipofectamine ${ }^{\circledR} 2000$ (Invitrogen; Thermo Fisher Scientific, Inc.) at $37^{\circ} \mathrm{C}$ with $100 \mathrm{ng}$ miR-494 mimics, anti-miR-494 or negative control mimics. A total of $4 \mathrm{~h}$ post-transfection, DMEM was removed and replaced with FBS-free DMEM; the cells were then treated with $100 \mathrm{ng} / \mathrm{ml}$ lipopolysaccharide (Beyotime Institute of Biotechnology, Haimen, China) to induce an in vitro SCI model, as reported in the literature (15), or with $10 \mu \mathrm{M} \mathrm{CAY} 10602$ at $37^{\circ} \mathrm{C}$ for $48 \mathrm{~h}$. After $4 \mathrm{~h}$ of transfection, cells were treated with the p53 agonist, $20 \mathrm{nM}$ Nutlin 3 (MCE China, Shanghai, China), for $44 \mathrm{~h}$ at $37^{\circ} \mathrm{C}$. In addition, to confirm that LPS induced an in vitro SCI model, PC12 cells were separated into the following two groups: The control group, in which cells were not treated with LPS; and the LPS group, in which cells were treated with $100 \mathrm{ng} / \mathrm{ml}$ LPS (Beyotime Institute of Biotechnology). 
ELISA kit. Cell supernatants were collected at 1,000 x $\mathrm{g}$ for $10 \mathrm{~min}$ at $4^{\circ} \mathrm{C}$ and were used to measure tumor necrosis factor (TNF)- $\alpha$ (cat. no. H052), interleukin (IL)-1 $\beta$ (cat. no. H002), IL-6 (cat. no. H007) and IL-18 (cat. no. H015) levels using ELISA kits (Nanjing Jiancheng Bioengineering Institute, Nanjing, China), according to the manufacturer's protocol. Absorbance was detected using an automatic multi-well spectrophotometer (Bio-Rad Laboratories, Inc., Hercules, CA, USA) at $450 \mathrm{~nm}$.

MTT assay and LDH activity assay. At different time points (24 and $48 \mathrm{~h}$ ) post-transfection, $20 \mu \mathrm{l} \mathrm{MTT}$ solution $(5 \mathrm{mg} / \mathrm{ml})$ was added to each well and incubated at $37^{\circ} \mathrm{C}$ for $4 \mathrm{~h}$. The culture medium was then removed and dimethyl sulfoxide was added to dissolve formazan for $20 \mathrm{~min}$ at $37^{\circ} \mathrm{C}$. The absorbance was detected using an automatic multi-well spectrophotometer (Bio-Rad Laboratories, Inc.) at $492 \mathrm{~nm}$.

A total of $48 \mathrm{~h}$ post-transfection, $\mathrm{LDH}$ activity was analyzed using LDH activity kits (cat. no. C0016, Beyotime Institute of Biotechnology), according to manufacturer's protocol, and absorbance was detected using an automatic multi-well spectrophotometer (Bio-Rad Laboratories, Inc.) at $450 \mathrm{~nm}$.

miR-494 target prediction and dual-luciferase reporter assay. miR-494 target prediction was conducted using TargetScan (http://www.targetscan.org/index.html) and miRanda (http://www.microrna.org). SIRT1 luciferase reporter plasmids containing the $3^{\prime}$ untranslated region targeting miR-494 $(100 \mathrm{ng})$ were co-transfected into the cells $\left(1 \times 10^{6} \mathrm{cell} / \mathrm{ml}\right)$ with $100 \mathrm{ng}$ of miRNA-494 mimics using Lipofectamine ${ }^{\circledR} 2000$ (Invitrogen; Thermo Fisher Scientific, Inc.) at $37^{\circ} \mathrm{C}$. Cells were plated in 24-well plates and were transfected for $48 \mathrm{~h}$. The Dual Luciferase Assay system (Promega Corporation) was used to measure luciferase reporter activities.

Apoptosis assay. Cells were washed with PBS for $5 \mathrm{~min}$ and fixed with $4 \%$ paraformaldehyde for $15 \mathrm{~min}$ at room temperature. Subsequently, cells were stained with $5 \mu 1$ Annexin V-phycoerythrin conjugate and $5 \mu 1$ propidium iodide (BD Biosciences, Franklin Lakes, NJ, USA) for $15 \mathrm{~min}$ in the dark at room temperature. Flow cytometry was performed using BD AccuriC6 (BD Biosciences) and data were analyzed by FlowJo 7.6.1 (FlowJo, LLC, Ashland, OR, USA).

Caspase-3/9 activity. Total protein was extracted using radioimmunoprecipitation assay buffer (Beyotime Institute of Biotechnology) and protein concentration was evaluated using the bicinchoninic acid assay (Beyotime Institute of Biotechnology), according to the manufacturer's protocols. Protein $(10 \mu \mathrm{g})$ was then used to measure caspase-3/9 activity using the Caspase-3/9 activity kits (cat. nos. C1115 and C1158; Beyotime Institute of Biotechnology), according to the manufacturer's protocol.

Western blot analysis. Total protein was extracted using radioimmunoprecipitation assay buffer (Beyotime Institute of Biotechnology) and protein concentration was evaluated using the bicinchoninic acid assay (Beyotime Institute of Biotechnology), according to the manufacturer's protocols. Proteins $(50 \mu \mathrm{g})$ were separated by $10 \%$ SDS-PAGE and were transferred to polyvinylidene difluoride membranes.
The membranes were then blocked with $5 \%$ non-fat dry milk in Tris-buffered saline- $0.1 \%$ Tween for $1 \mathrm{~h}$ at $37^{\circ} \mathrm{C}$, and were incubated with primary antibodies against SIRT1 (cat. no. sc-135792, 1:1,000), cyclin E (cat. no. sc-48420, 1:1,000), p53 (cat. no. sc-47698, 1:1,000), Bax (cat. no. sc-20067, $1: 1,000)$, p21 (cat. no. sc-817, 1:1,000) and GAPDH (cat. no. sc-51631, 1:5,000) (all Santa Cruz Biotechnology, Inc., Dallas, TX, USA) at $4^{\circ} \mathrm{C}$ overnight. After washing with PBST for $15 \mathrm{~min}$, membranes were incubated with a horseradish peroxidase-conjugated anti-mouse secondary antibody (cat. no. sc-2005, 1:5,000; Santa Cruz Biotechnology, Inc.) for $1 \mathrm{~h}$ at $37^{\circ} \mathrm{C}$. Proteins were visualized using an enhanced chemiluminescence kit (Pierce; Thermo Fisher Scientific, Inc.) and were analyzed using Image Lab 3.0 (Bio-Rad Laboratories, Inc.).

Immunofluorescence staining. Cells were washed with PBS for $5 \mathrm{~min}$ and fixed with $4 \%$ paraformaldehyde for $15 \mathrm{~min}$ at room temperature. Subsequently, cells were penetrated with $0.25 \%$ Triton X-100 in PBS for $15 \mathrm{~min}$ at room temperature, washed with PBS for $15 \mathrm{~min}$, and blocked with $5 \%$ bovine serum albumin (Beyotime Institute of Biotechnology) in PBS for $1 \mathrm{~h}$ at $37^{\circ} \mathrm{C}$. The cells were then incubated with anti-SIRT1 (cat. no. sc-135792, 1:100; Santa Cruz Biotechnology, Inc.) at $4^{\circ} \mathrm{C}$ overnight, washed with PBS for $15 \mathrm{~min}$, and incubated with goat anti-mouse immunoglobulin G-CruzFluor ${ }^{\mathrm{TM}} 555$ (cat. no. sc-362267, 1:5,000; Santa Cruz Biotechnology, Inc.) for $1 \mathrm{~h}$ at room temperature. Finally, cells were washed for 15 min and incubated with DAPI in the dark. Cells were observed using confocal microscopy (Leica SP5, Argon laser; Leica Microsystems, Inc., Buffalo Grove, IL, USA).

Statistical analysis. All data are presented as the means \pm standard deviation $(n=3)$, and were analyzed using SPSS 17.0 (SPSS, Inc., Chicago, IL, USA). Data were compared using two-tailed Student's t-test or one-way analysis of variance and Tukey's post hoc test. $\mathrm{P}<0.05$ was considered to indicate a statistically significant difference.

\section{Results}

SIRT1 and miR-494 expression in the SCI rat model. The present study evaluated the expression levels of SIRT1 in SCI tissues using qPCR. Hematoxylin and eosin staining indicated that inflammation was markedly increased in SCI tissues compared with in the control group (Fig. 1A). Furthermore, water content in the spinal cord was increased, and the BBB score was reduced in SCI tissues, compared with in the control group (Fig. 1B and C). As shown in Fig. 1D-F, the mRNA and protein expression levels of SIRT1 in SCI tissues were significantly inhibited compared with in the control group. Subsequently, a gene chip was used to analyze the alterations in miRNA expression in SCI tissues; it was revealed that miR-494 expression was increased in rats in the SCI group compared with in the control group (Fig. $1 \mathrm{G}$ and $\mathrm{H}$ ). These results indicated that an association may exist between miR-494 and SIRT1 in SCI.

miR-494 regulates SIRT1 expression in an SCI model. Initially, it was revealed that LPS induced an increase in 


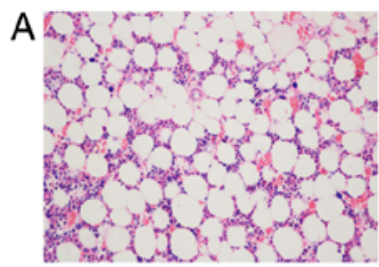

Control

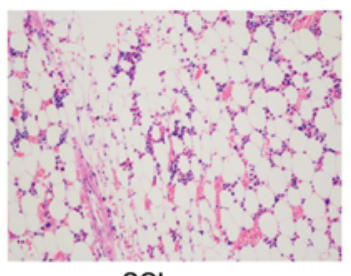

$\mathrm{SCl}$
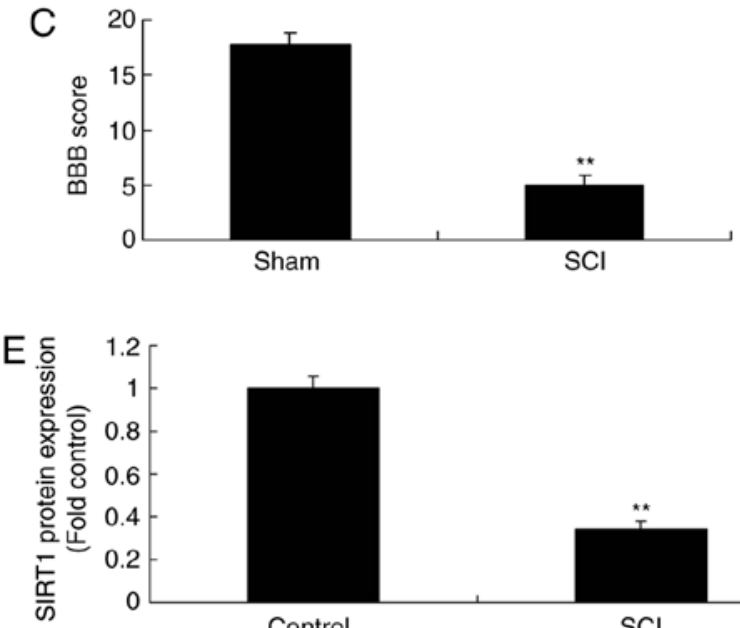

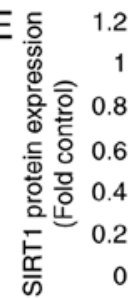
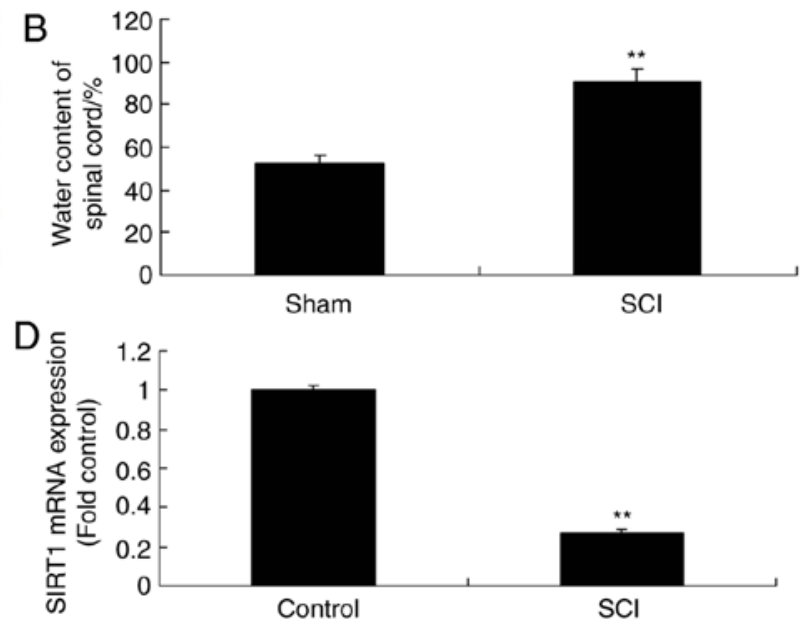

Sham

$\mathrm{SCl}$

$\mathrm{F}$
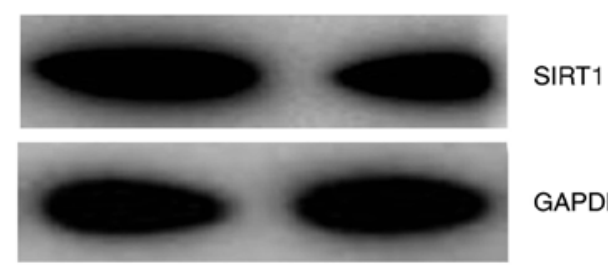

GAPDH

$\mathrm{SCl}$

G

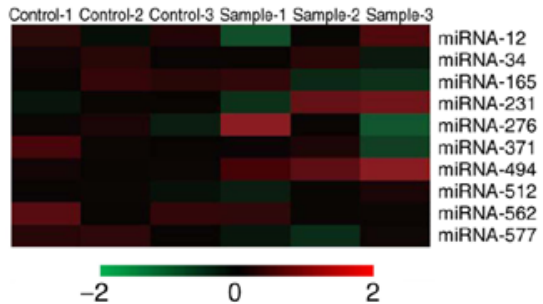

$\mathrm{H}$

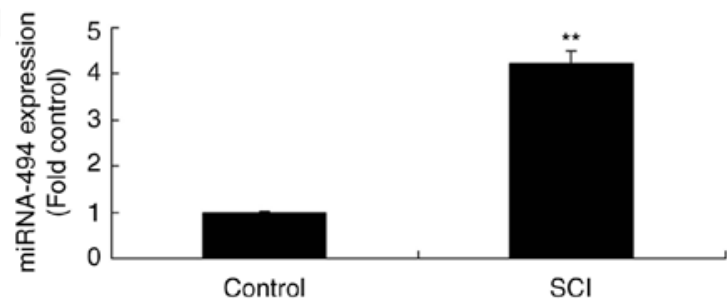

Figure 1. SIRT1 and miRNA-494 expression in the SCI rat model. (A) Hematoxylin and eosin staining of the spinal cord (magnification, x100) and (B) water content of the spinal cord. (C) BBB score. (D) SIRT1 mRNA and (E and F) protein expression. (G) Gene chip analysis of miRNA expression. (H) miRNA-494 expression, as determined by quantitative polymerase chain reaction. ${ }^{* *} \mathrm{P}<0.01$ compared with the control group. miRNA-494, microRNA-494; SCI, spinal cord injury; SIRT1, sirtuin 1 .
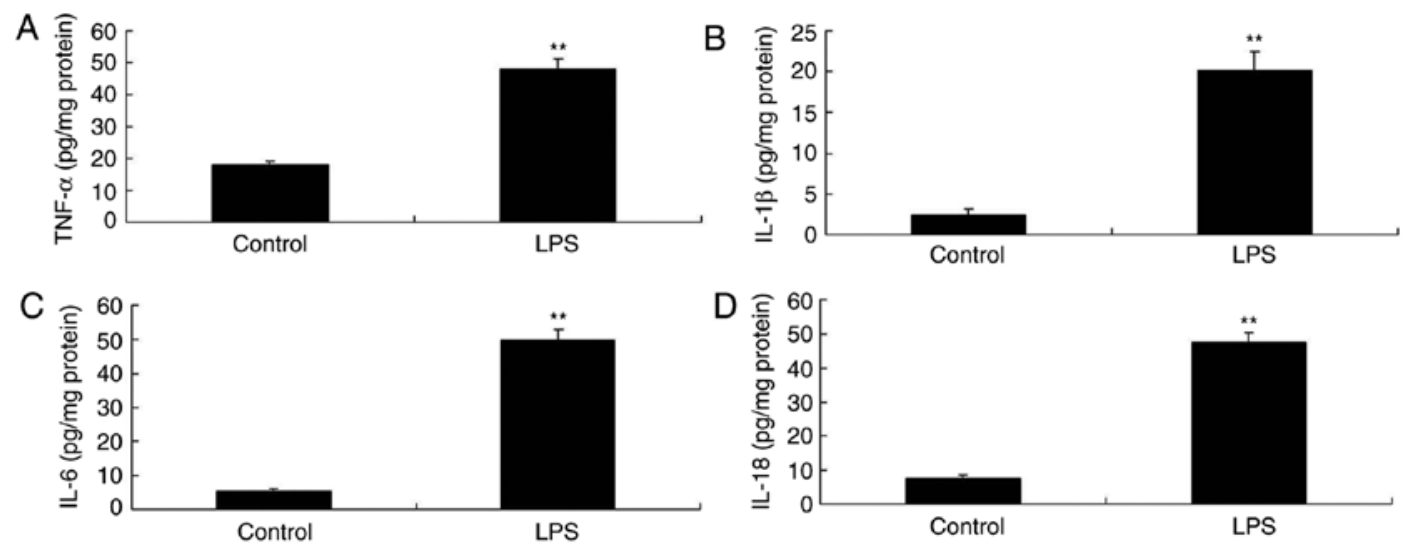

Figure 2. LPS induces inflammation in PC12 cells. (A) TNF- $\alpha$, (B) IL-1 $\beta$, (C) IL-6 and (D) IL-18 levels in PC12 cells. Control, PC12 cell without LPS group; LPS, LPS-treated PC12 cell group. ${ }^{* *} \mathrm{P}<0.01$ compared with the control group. IL, interleukin; LPS, lipopolysaccharide; TNF- $\alpha$, tumor necrosis factor- $\alpha$.

tumor necrosis factor (TNF)- $\alpha$, interleukin (IL)-1 $\beta$, IL-6 and IL-18 levels in PC12 cells compared with in the control group (Fig. 2). Subsequently, in the in vitro model, SIRT1 was identified as a direct target of miR-494 and inhibited luciferase activity (Fig. 3A and B). miR-494 mimics and anti-miR-494 mimics were separately transfected into cells, and increased or decreased miR-494 expression compared with in the control group, respectively (Fig. 3C and D). Following miR-494 overexpression, a gene chip analysis was conducted, which revealed that SIRT1 mRNA expression was suppressed in the 


\section{A MicroRNA-494---GGAAAUGUUUCA.... SIRT1---CACAUACAAAGU....}
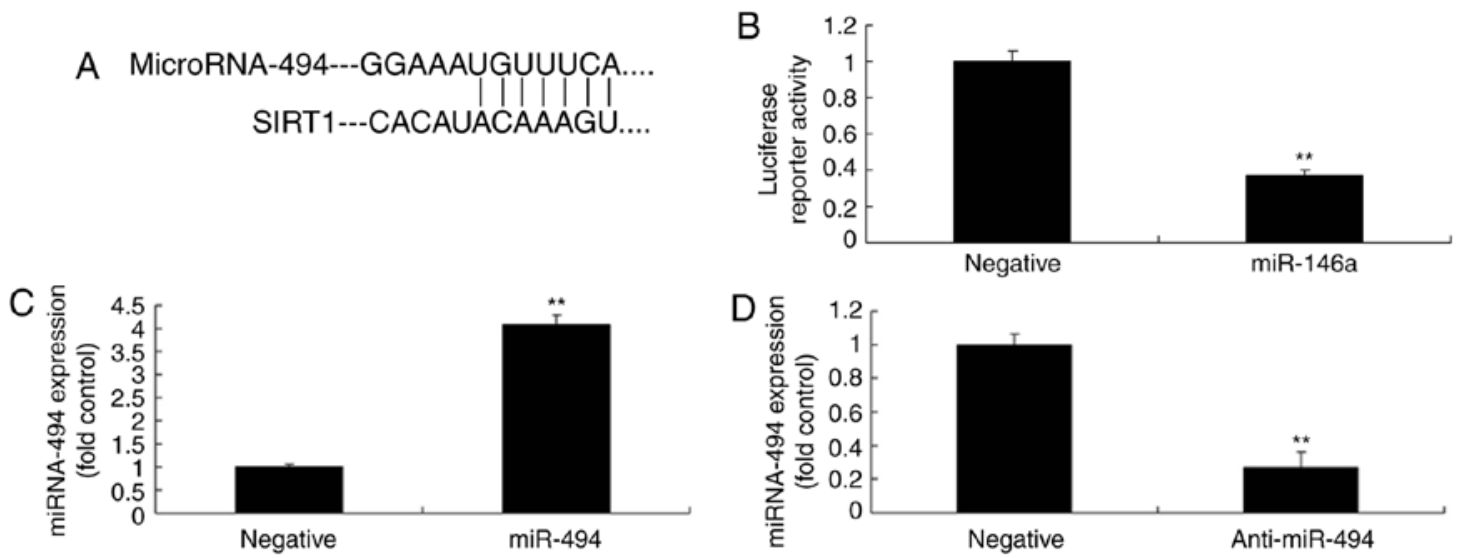

E Control-1 Control-2 Control-3 Sample-1 Sample-2 Sample-3
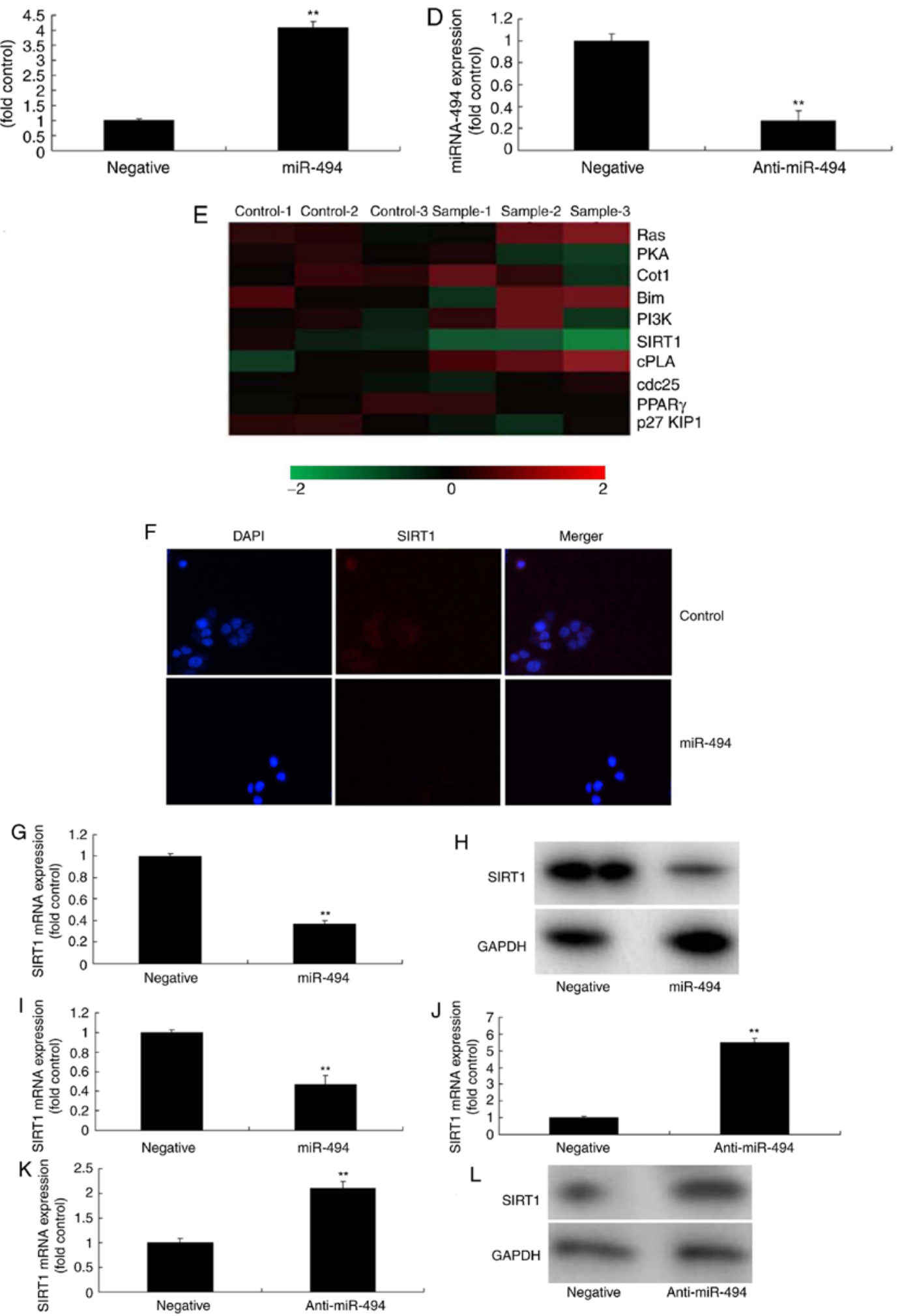

Figure 3. miR-494 regulates SIRT1 expression in the spinal cord injury model. (A) SIRT1 was identified as a direct target gene of miR-494 and (B) luciferase activity was measured. (C and D) miR-494 expression was determined by quantitative polymerase chain reaction. (E) Gene chip analysis of SIRT1 expression. (F) Immunofluorescence analysis of SIRT1 protein expression. Magnification, x100. (G and H) SIRT1 protein and (I) mRNA expression was suppressed following overexpression of miRNA-494. (J) SIRT1 mRNA and (K and L) protein expression was increased following downregulation of miRNA-494. ${ }^{* *} \mathrm{P}<0.01$ compared with the negative mimics group. miRNA/miR-494, microRNA-494; SIRT1, sirtuin 1. 

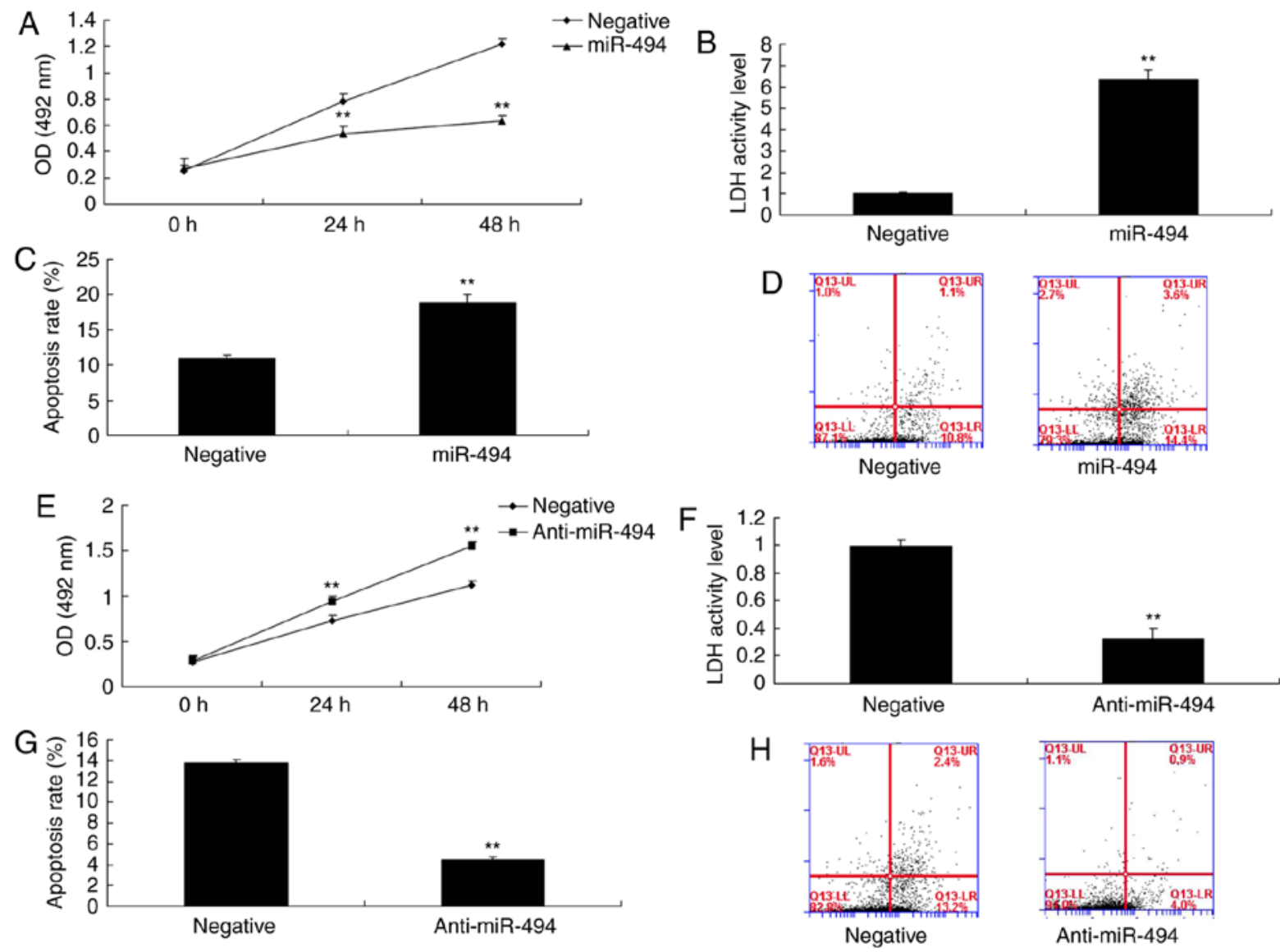

Figure 4. miR-494 regulates cell apoptosis in an in vitro model of spinal cord injury. (A) Cell growth was inhibited, and (B) LDH activity and (C and D) cell apoptosis were increased by miR-494 overexpression. (E) Cell growth was increased, and (F) LDH activity and (G and H) cell apoptosis were decreased by miR-494 knockdown. ${ }^{* *} \mathrm{P}<0.01$ compared with the negative mimics group. LDH, lactate dehydrogenase; miR-494, microRNA-494; OD, optical density.

in vitro model compared with in the control group (Fig. 3E). Western blotting and immunofluorescence revealed that miR-494 overexpression suppressed SIRT1 protein expression in vitro, in comparison with the control group (Fig. 3F-H). However, miR-494 downregulation induced SIRT1 mRNA and protein expression in vitro compared with in the control group (Fig. 3I-L).

miR-494 regulates cell apoptosis in an in vitro model of SCI. To determine the effects of miR-494 on the SCI model, cell apoptosis and cell growth were analyzed. As shown in Fig. 4A-D, overexpression of miR-494 promoted cell apoptosis and LDH activity, and inhibited cell growth compared with in the negative control group. Conversely, miR-494 knockdown promoted cell growth, and inhibited cell apoptosis and LDH activity in the SCI model compared with in the negative control group (Fig. 4E-H).

miR-494 regulates the p53 signaling pathway in an in vitro model of SCI. To further explore the mechanism underlying the effects of miR-494 on SCI, the p53 signaling pathway was analyzed in the SCI model. As shown in Fig. 5, overexpression of miR-494 induced the protein expression of p53, Bax, and p21, suppressed cyclin E protein expression, and increased caspase-3/9 activity in the SCI model compared with in the negative control group. Conversely, miR-494 knockdown suppressed the protein expression of $\mathrm{p} 53$, Bax and $\mathrm{p} 21$, induced cyclin E protein expression, and decreased caspase-3/9 activity in the SCI model compared with in the negative control group (Fig. 6). Collectively, these results indicated that miR-494 may mediate nerve cell apoptosis in SCI through the p53 signaling pathway via SIRT1.

SIRT1 agonist attenuates the effects of miR-494 on cell apoptosis in SCI. The present study explored the role of SIRT1 in the effects of miR-494; the in vitro model of SCI was treated with a SIRT1 agonist, CAY10602 $(10 \mu \mathrm{M})$, following miR-494 transfection. As shown in Fig. 7, the SIRT1 agonist increased the protein expression levels of SIRT1 and cyclin $\mathrm{E}$, and suppressed $\mathrm{p} 53, \mathrm{Bax}$ and $\mathrm{p} 21$ protein expression in the SIRT1 + miR-494 group compared with in the miR-494 group. Treatment with the SIRT1 agonist also decreased cell apoptosis, LDH activity and caspase-3/9 activity, and increased cell growth in the SIRT1 + miR-494 group compared with in the miR-494 group (Fig. 8). Overall, these results indicated that SIRT1 may be a direct target gene of miR-494, which regulates nerve cell apoptosis in SCI.

p53 agonist attenuates the effects of anti-miR-494 on cell apoptosis in SCI. Finally, a p53 agonist, $20 \mathrm{nM}$ Nutlin 3, was revealed to increase the protein expression levels of $\mathrm{p} 53$, Bax and $\mathrm{p} 21$, and suppress cyclin E protein expression in the 

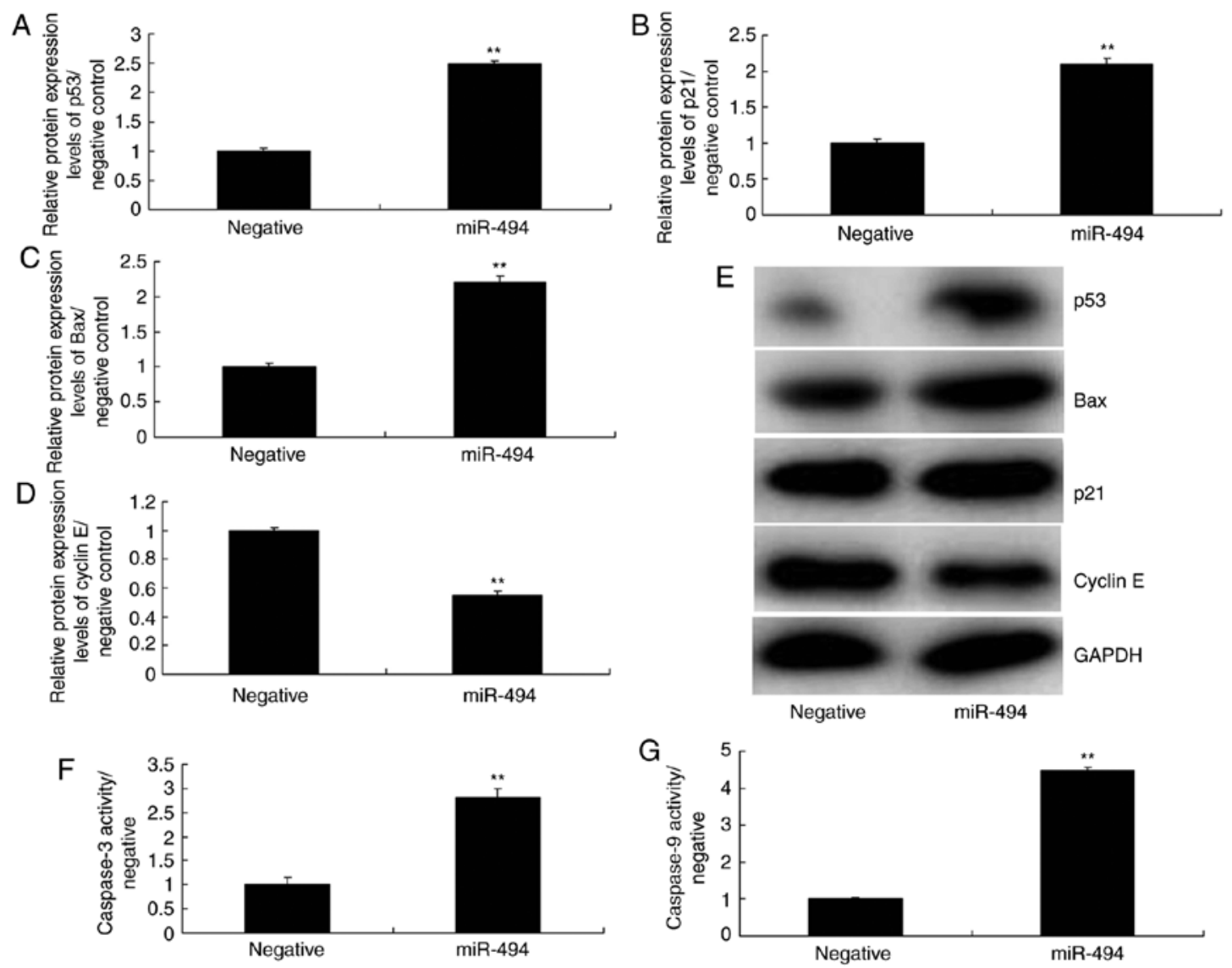

Figure 5. Overexpression of miR-494 regulates the p53 signaling pathway in spinal cord injury. (A) p53, (B) p21, (C) Bax and (D) cyclin E protein expression levels were semi-quantified following (E) western blotting. ( $\mathrm{F}$ and $\mathrm{G})$ Caspase-3/9 activity levels were detected. ${ }^{* *} \mathrm{P}<0.01$ compared with the negative mimics group. Bax, B-cell lymphoma 2-associated X protein; miR-494, microRNA-494.
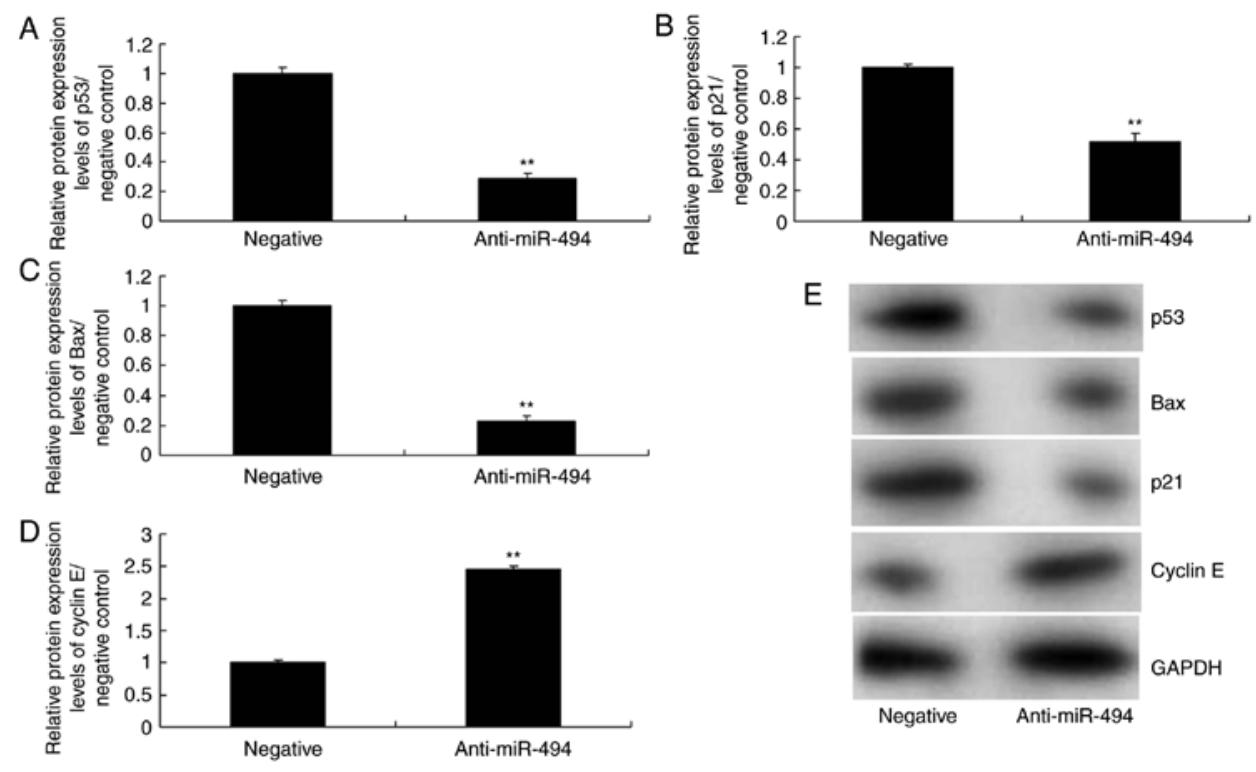

E
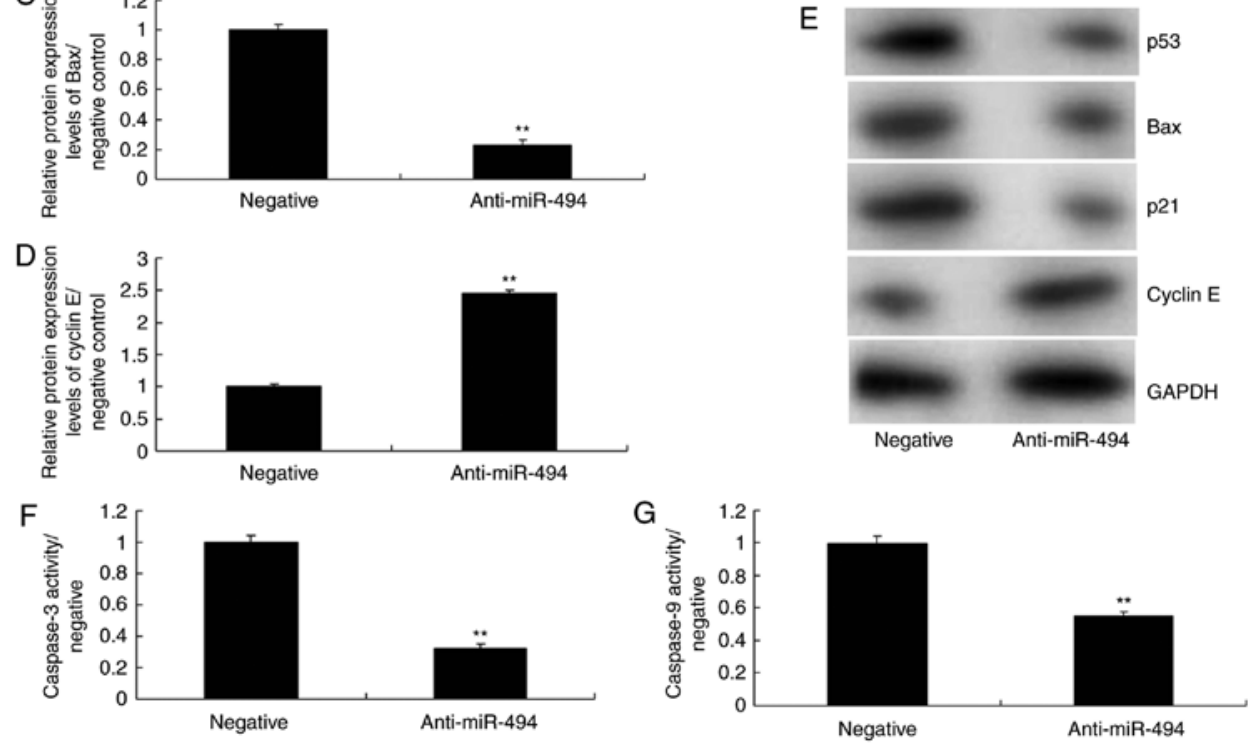

Figure 6. Knockdown of miR-494 regulates the p53 signaling pathway in spinal cord injury. (A) p53, (B) p21, (C) Bax and (D) cyclin E protein expression levels were semi-quantified following (E) western blotting. ( $\mathrm{F}$ and $\mathrm{G}$ ) Caspase-3/9 activity levels were detected. ${ }^{* *} \mathrm{P}<0.01$ compared with the negative mimics group. Bax, B-cell lymphoma 2-associated X protein; miR-494, microRNA-494. 

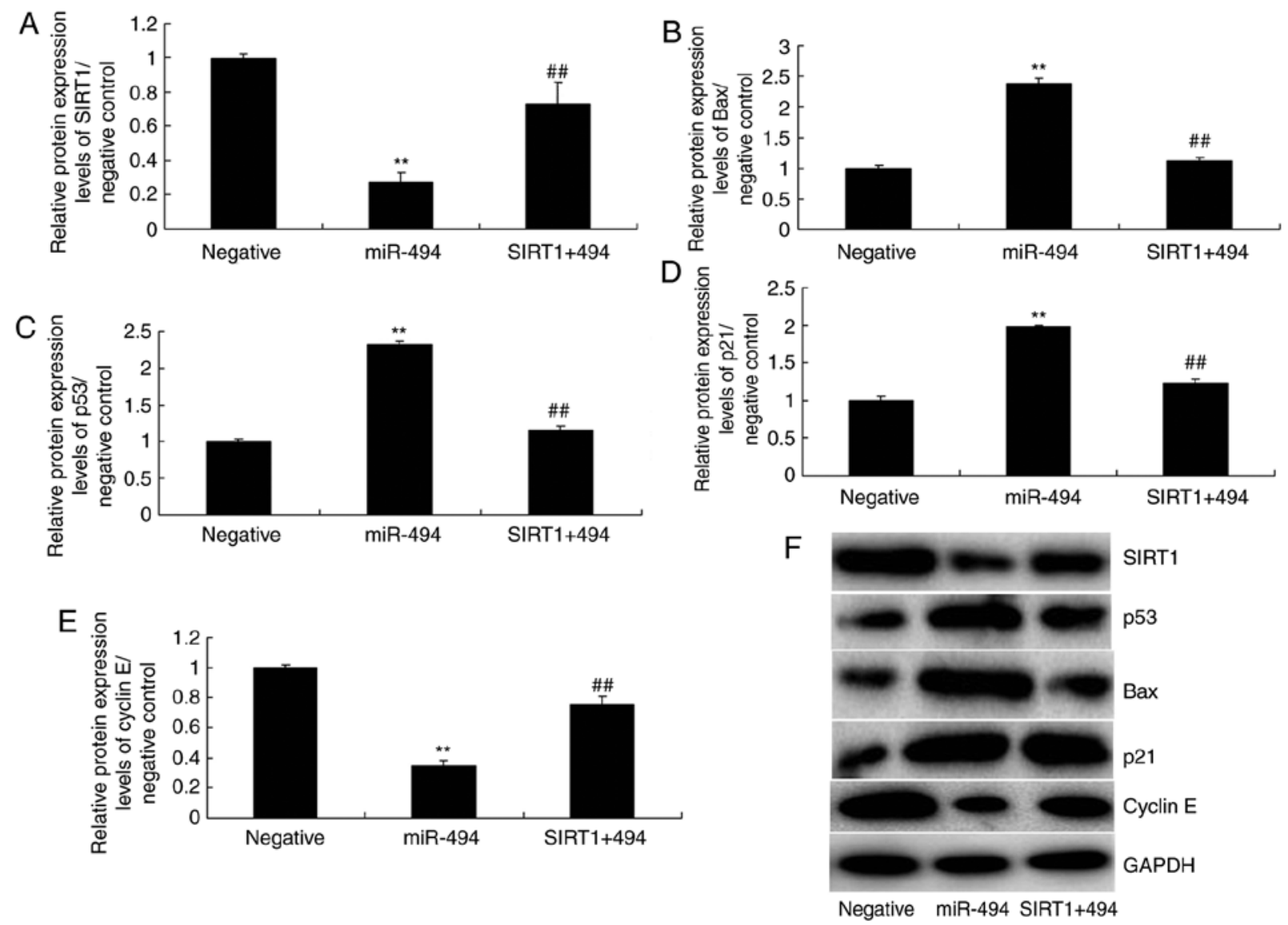

Figure 7. SIRT1 agonist reduces the effects of miR-494 on the SIRT1 signaling pathway in spinal cord injury. (A) SIRT1, (B) Bax, (C) p53, (D) p21 and (E) cyclin $\mathrm{E}$ protein expression levels were semi-quantified following $(\mathrm{F})$ western blotting. ${ }^{* *} \mathrm{P}<0.01$ compared with the negative mimics group; ${ }^{\# \#} \mathrm{P}<0.01$ compared with the miR-494 group. Bax, B-cell lymphoma 2-associated X protein; miR-494, microRNA-494; SIRT1, sirtuin 1.
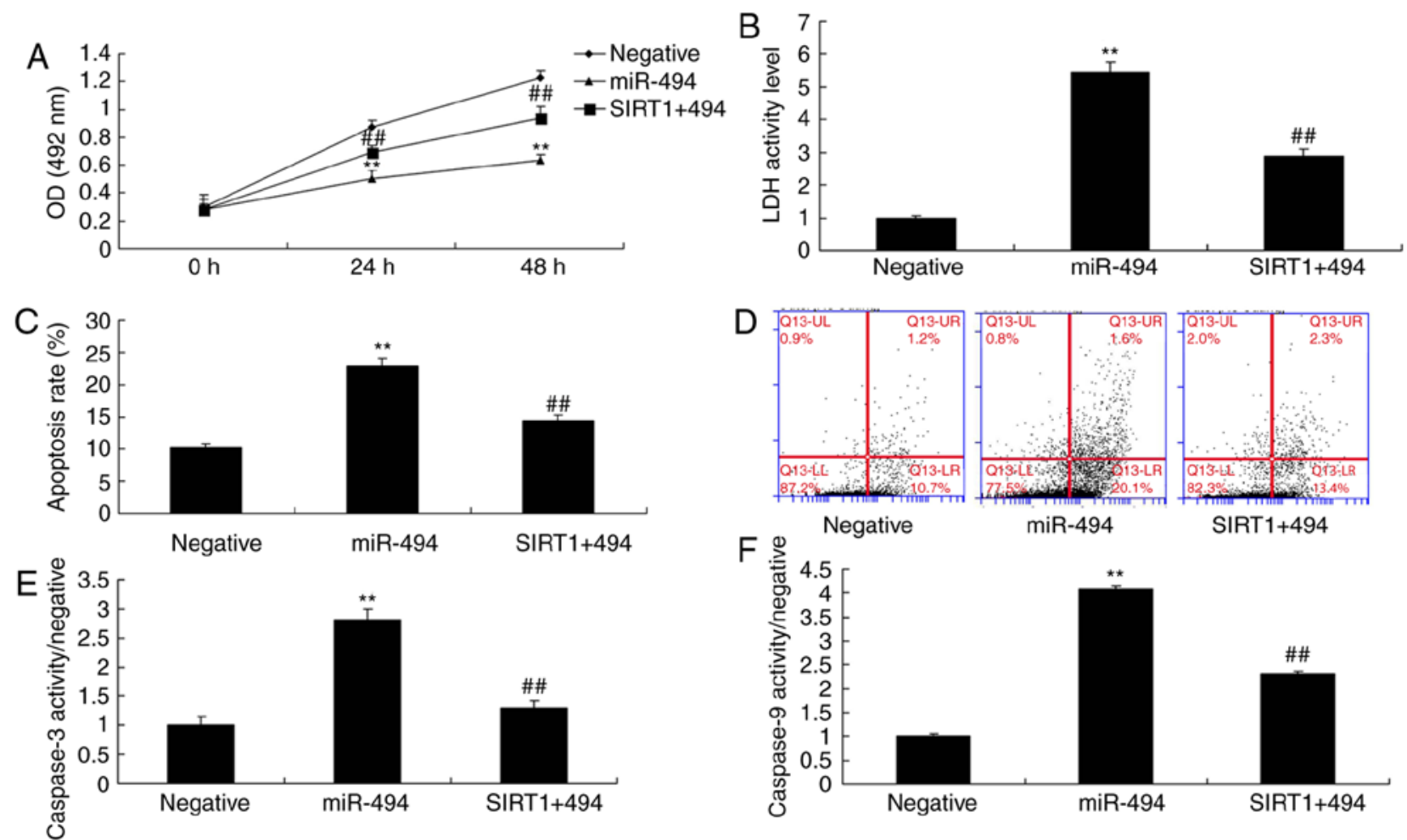

Figure 8. SIRT1 agonist reduces the effects of miR-494 on cell apoptosis in spinal cord injury. (A) Cell growth, (B) LDH activity, (C and D) cell apoptosis, and (E and F) caspase-3/9 activity were analyzed. ${ }^{* *} \mathrm{P}<0.01$ compared with the negative mimics group; ${ }^{\# \#} \mathrm{P}<0.01$ compared with the miR-494 group. $\mathrm{LDH}$, lactate dehydrogenase; miR-494, microRNA-494; OD, optical density; SIRT1, sirtuin 1. 

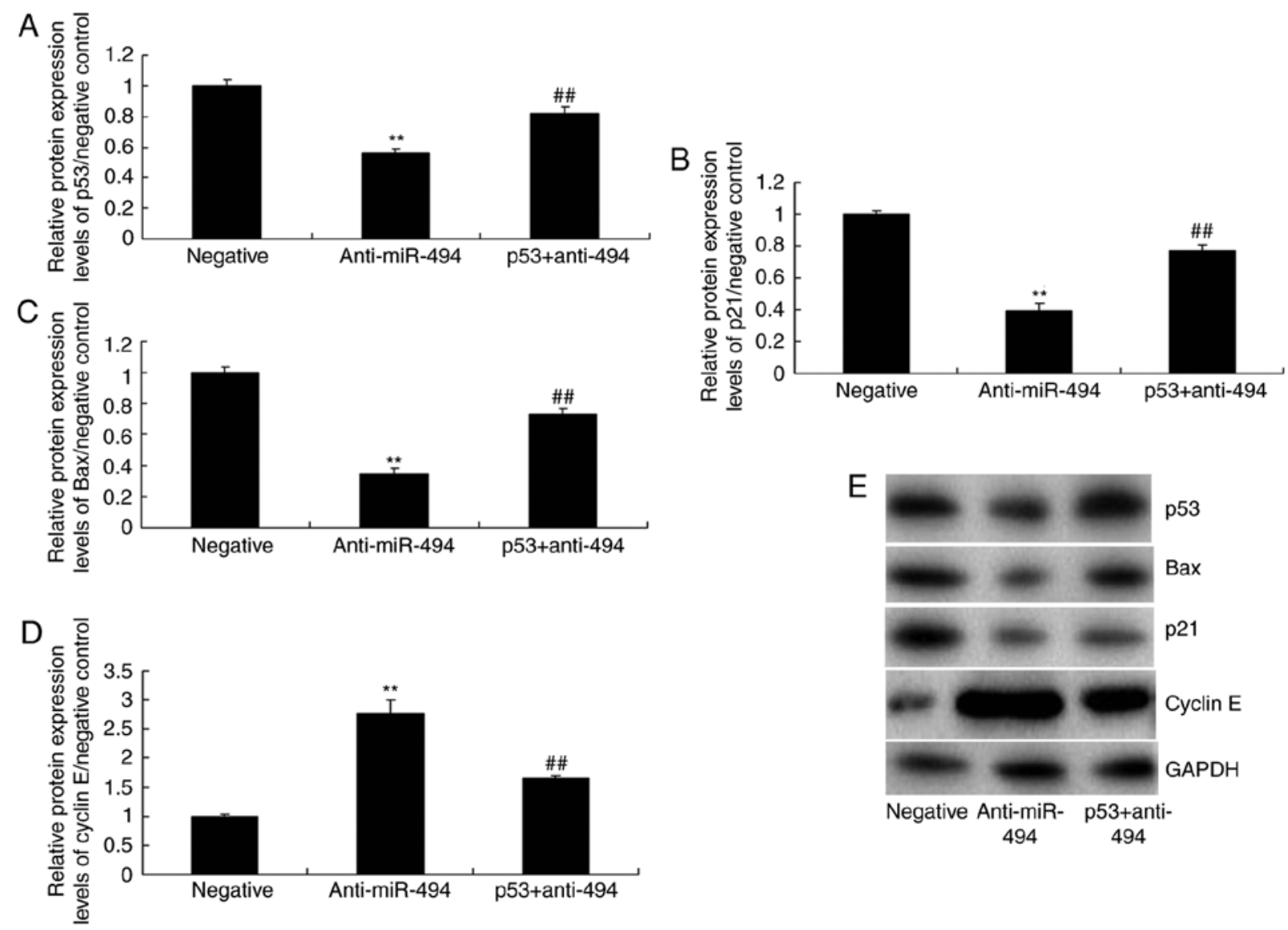

Figure 9. p53 agonist reduces the effects of anti-miR-494 on sirtuin 1 signaling in spinal cord injury. (A) p53, (B) p21, (C) Bax and (D) cyclin E protein expres-

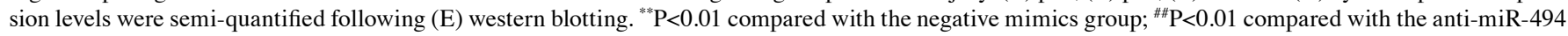
group. Bax, B-cell lymphoma 2-associated X protein; miR-494, microRNA-494.
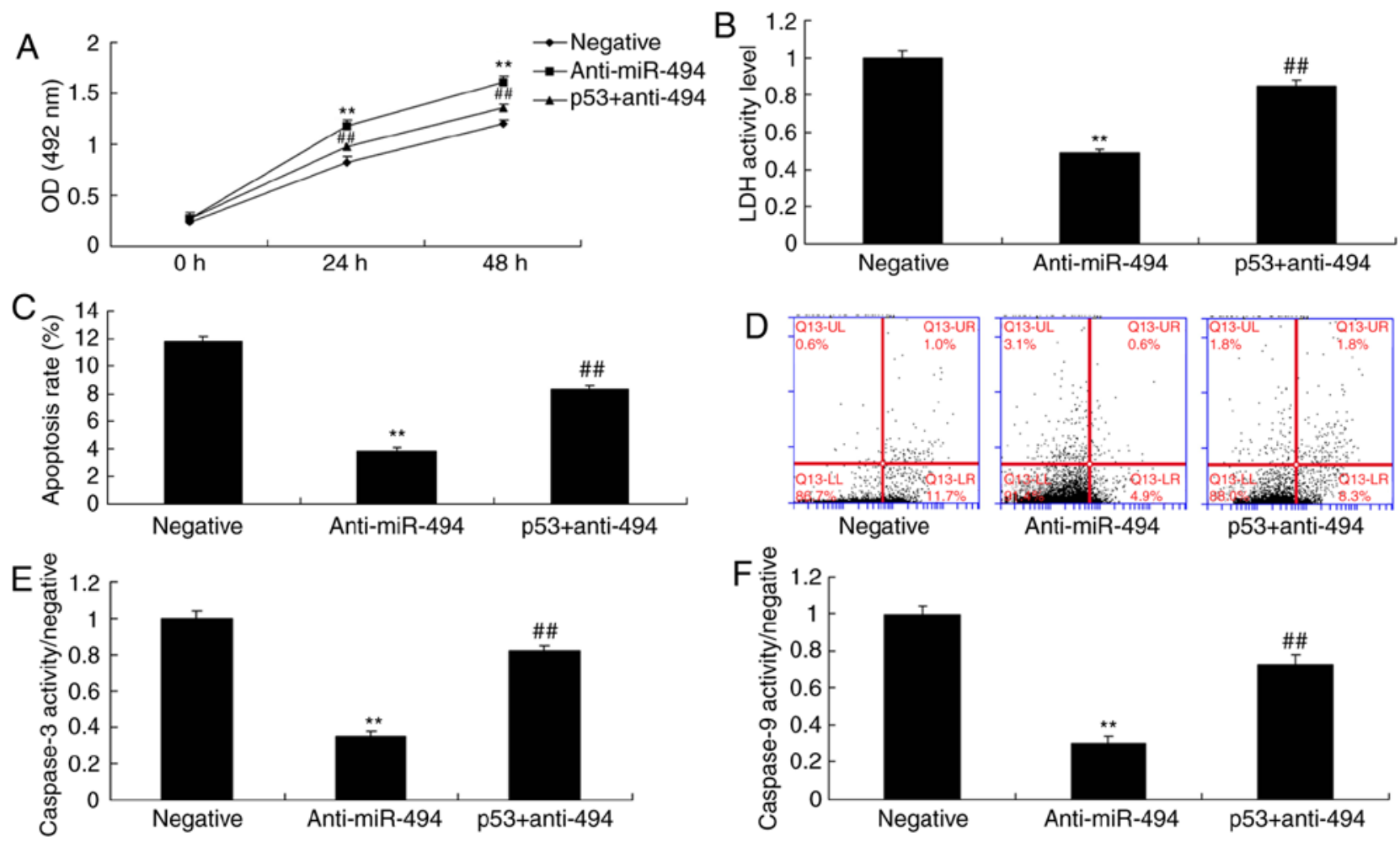

Figure 10. p53 agonist reduces the effects of anti-miR-494 on cell apoptosis in spinal cord injury. (A) Cell growth, (B) LDH activity, (C and D) cell apoptosis, and $(\mathrm{E}$ and $\mathrm{F})$ caspase-3/9 activity were analyzed. ${ }^{* *} \mathrm{P}<0.01$ compared with the negative mimics group; ${ }^{\# \#} \mathrm{P}<0.01$ compared with the anti-miR-494 group. LDH, lactate dehydrogenase; miR-494, microRNA-494; OD, optical density. 


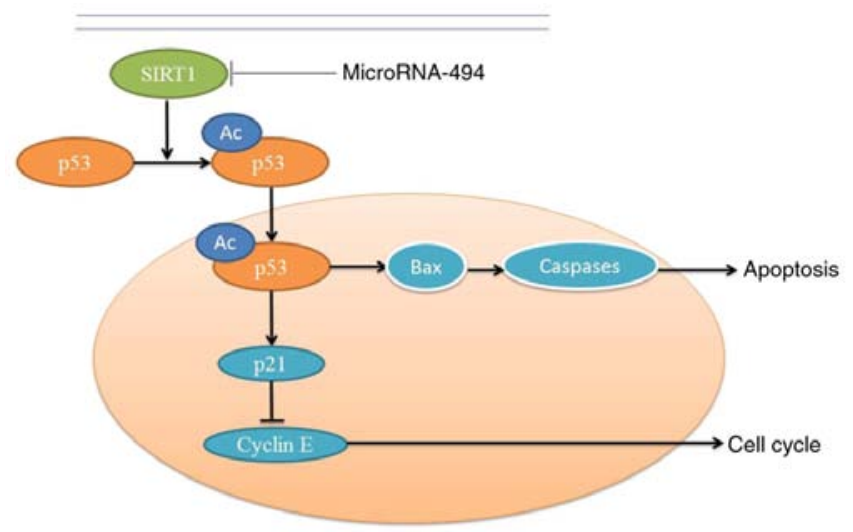

Figure 11. SIRT1 inhibits apoptosis of spinal cord injury in vivo and in vitro, whereas microRNA-494 can suppress SIRT1 and induce apoptosis. Bax, B-cell lymphoma 2-associated X protein; SIRT1, sirtuin 1.

p53 + anti-miR-494 group compared with in the anti-miR-494 group (Fig. 9). The p53 agonist also decreased cell growth, and induced cell apoptosis, LDH activity and caspase-3/9 activity in the p53 + anti-miR-494 group, compared with in the anti-miR-494 group (Fig. 10). Taken together, these findings suggested that p53 may promote nerve cell apoptosis in SCI via SIRT1/miR-494.

\section{Discussion}

SCI induces the cellular oxidative stress response, necrosis and apoptosis. Furthermore, a large number of inflammatory mediators are locally produced in response to SCI, thus resulting in the immune inflammatory response (4). In such secondary injury, the inflammatory response serves a crucial role in post-SCI recovery (13). Control and inhibition of the inflammatory response therefore affects post-SCI recovery. miRNAs are small RNA molecules that regulate target gene expression (14). In addition, miRNAs have a vital role in gene expression during spinal development and SCI (15); therefore, they may be considered a novel target for therapeutic intervention in post-SCI nerve regeneration and repair. Furthermore, miRNAs may be potential biological markers of SCI. The present study demonstrated that overexpression of miR-494 promoted cell apoptosis and LDH activity, and inhibited cell growth in an SCI model compared with in the negative control group. Kang et al (16) revealed that microRNA-494 promotes apoptosis in degenerative human nucleus pulposus cells. Zhan et al (17) suggested that miR-494 inhibits breast cancer progression and induces apoptosis by directly targeting p21 (RAC1)-activated kinase 1.

The SIRT1 anti-inflammatory mechanism is complex and involves numerous pathways, including the mitogen-activated protein kinase and $\mathrm{NF}-\kappa \mathrm{B}$ pathways (8). Furthermore, it has been suggested that the cyclooxygenase pathway may also be involved (8). At present, the NF- $\mathrm{NB}$ pathway has been most extensively studied. However, the inflammatory pathway is a multi-channel reticular structure (18), as a result, it is not determined by a certain pathway. The mechanism underlying inflammation will become increasingly clear with research on each pathway, and the reticular structure of the inflammatory pathway will be elucidated (19); therefore, it will be more easily controlled. SIRT1 can downregulate the proapoptotic effects of p53 through its deacetylation. At present, p53 is one of the most extensively and profoundly studied tumor suppressor genes in human research (20). Furthermore, p53 participates in cell differentiation, proliferation, aging and mortality (20), and is involved in gene transcription, DNA damage and repair, genomic stability and cell cycle control (21). The present study demonstrated that overexpression of miR-494 suppressed SIRT1 protein expression in an in vitro model compared with in the control group. Liu et al (22) indicated that miR-494 inhibits the proliferation, invasion and chemoresistance of pancreatic cancer through SIRT1.

Neuronal apoptosis is suppressed following nervous system injury (23). However, several proteins and nuclear transcription factors are specifically expressed in a delayed manner; 553 is one of the key molecules in the cell apoptosis pathway. Upregulated p53 expression can directly induce cell apoptosis (23). In addition, it can induce cell apoptosis through regulating the expression of other apoptosis-associated genes (19). The present study demonstrated that overexpression of miR-494 induced p53, Bax and p21 protein expression, suppressed cyclin $\mathrm{E}$ protein expression, and increased caspase-3/9 activity in an SCI model. Comegna et al revealed that direct targets of miR-494 are involved in senescence of human diploid fibroblasts via p53 protein expression (24).

In conclusion, the present study indicated that SIRT1 may inhibit apoptosis of SCI in vivo and in vitro through the $\mathrm{p} 53$ signaling pathway, whereas miR-494 may suppress SIRT1 and induce apoptosis (Fig. 11). Mechanistically, the present study demonstrated that miR-494 promoted neurocyte apoptosis through directly targeting the SIRT1/p53 signaling pathway. These results suggested that the miR-494/SIRT1/p53 signaling pathway may be a potential clinical biomarker and therapeutic target in SCI.

\section{Acknowledgements}

Not applicable.

\section{Funding}

No funding was received.

\section{Availability of data and materials}

The datasets used and/or analyzed during the current study are available from the corresponding author on reasonable request.

\section{Authors' contributions}

$X Y$ designed the experiment, analyzed the data and wrote the manuscript. SZ, DZ, XZ, CX, TW, MZ, TL, WH and BW performed the experiments. All authors read and approved the final manuscript.

\section{Ethics approval and consent to participate}

The present study was approved by the Scientific Review Committee and the Institutional Review Board of Dalian University. 


\section{Patient consent for publication}

Not applicable.

\section{Competing interests}

The authors declare that they have no competing interests.

\section{References}

1. Ancha HR, Spungen AM, Bauman WA, Rosman AS, Shaw S, Hunt KK, Post JB, Galea M and Korsten MA: Clinical trial: The efficacy and safety of routine bowel cleansing agents for elective colonoscopy in persons with spinal cord injury-a randomized prospective single-blind study. Aliment Pharmacol Ther 30: 1110-1117, 2009.

2. Apostolidis A, Thompson C, Yan X and Mourad S: An exploratory, placebo-controlled, dose-response study of the efficacy and safety of onabotulinumtoxin A in spinal cord injury patients with urinary incontinence due to neurogenic detrusor overactivity. World J Urol 31: 1469-1474, 2013.

3. Grossman RG, Fehlings MG, Frankowski RF, Burau KD, Chow DS, Tator C, Teng A, Toups EG, Harrop JS, Aarabi B, et al: A prospective, multicenter, phase I matched-comparison group trial of safety, pharmacokinetics, and preliminary efficacy of riluzole in patients with traumatic spinal cord injury. J Neurotrauma 31: 239-255, 2014.

4. Yang ML, Li JJ, So KF, Chen JY, Cheng WS, Wu J, Wang ZM, Gao F and Young W: Efficacy and safety of lithium carbonate treatment of chronic spinal cord injuries: A double-blind, randomized, placebo-controlled clinical trial. Spinal Cord 50: 141-146, 2012.

5. Celik EC, Erhan B, Gunduz B and Lakse E: The effect of low-frequency TENS in the treatment of neuropathic pain in patients with spinal cord injury. Spinal Cord 51: 334-337, 2013.

6. Liang Q, Dong S, Lei L, Liu J, Zhang J, Li J, Duan J and Fan D: Protective effects of sparstolonin B, a selective TLR2 and TLR4 antagonist, on mouse endotoxin shock. Cytokine 75: 302-309, 2015.

7. Deng X, Zhang Y, Jiang F, Chen R, Peng P, Wen B and Liang J: The chinese herb-derived sparstolonin B suppresses HIV-1 transcription. Virol J 12: 108, 2015.

8. Liu Q, Li J, Liang Q, Wang D, Luo Y, Yu F, Janicki JS and Fan D: Sparstolonin B suppresses rat vascular smooth muscle cell proliferation, migration, inflammatory response and lipid accumulation. Vascul Pharmacol 67-69: 59-66, 2015.

9. Li XQ, Lv HW, Tan WF, Fang B, Wang H and Ma H: Role of the TLR4 pathway in blood-spinal cord barrier dysfunction during the bimodal stage after ischemia/reperfusion injury in rats. J Neuroinflammation 11: 62, 2014.

10. Wright KR, Mitchell B and Santanam N: Redox regulation of microRNAs in endometriosis-associated pain. Redox Biol 12: 956-966, 2017.

11. Livak KJ and Schmittgen TD: Analysis of relative gene expression data using real-time quantitative PCR and the 2(-Delta Delta C(T)) method. Methods 25: 402-408, 2001.

12. Li G, Chen T, Zhu Y, Xiao X, Bu J and Huang Z: miR-103 alleviates autophagy and apoptosis by regulating SOX2 in LPS-injured PC12 cells and SCI rats. Iran J Basic Med Sci 21: 292-300, 2018
13. Van Straaten MG, Cloud BA, Morrow MM, Ludewig PM and Zhao KD: Effectiveness of home exercise on pain, function, and strength of manual wheelchair users with spinal cord injury: A high-dose shoulder program with telerehabilitation. Arch Phys Med Rehabil 95: 1810-1817 e1812, 2014.

14. Freria CM, Bernardes D, Almeida GL, Simoes GF, Barbosa GO and Oliveira AL: Impairment of toll-like receptors 2 and 4 leads to compensatory mechanisms after sciatic nerve axotomy. J Neuroinflammation 13: 118, 2016.

15. Lobenwein D, Tepekoylu C, Kozaryn R, Pechriggl EJ, Bitsche M, Graber M, Fritsch H, Semsroth S, Stefanova N, Paulus P, et al: Shock wave treatment protects from neuronal degeneration via a Toll-Like receptor 3 dependent mechanism: Implications of a first-ever causal treatment for ischemic spinal cord injury. J Am Heart Assoc 4: e002440, 2015.

16. Kang L, Yang C, Song Y, Zhao K, Liu W, Hua W, Wang K, Tu J, Li S, Yin H and Zhang Y: MicroRNA-494 promotes apoptosis and extracellular matrix degradation in degenerative human nucleus pulposus cells. Oncotarget 8: 27868-27881, 2017.

17. Zhan MN, Yu XT, Tang J, Zhou CX, Wang CL, Yin QQ, Gong XF, He M, He JR, Chen GQ and Zhao Q: MicroRNA-494 inhibits breast cancer progression by directly targeting PAK1. Cell Death Dis 8: e2529, 2017.

18. Ak H, Gulsen I, Karaaslan T, Alaca İ, Candan A, Koçak H, Atalay T, Çelikbilek A, Demir İ and Yılmaz T: The effects of caffeic acid phenethyl ester on inflammatory cytokines after acute spinal cord injury. Ulus Travma Acil Cerrahi Derg 21: 96-101,2015.

19. Kim DI, Lee H, Lee BS, Kim J and Jeon JY: Effects of a 6-week indoor hand-bike exercise program on health and fitness levels in people with spinal cord injury: A randomized controlled trial study. Arch Phys Med Rehabil 96: 2033-2040 e2031, 2015.

20. Wadsworth BM, Haines TP, Cornwell PL, Rodwell LT and Paratz JD: Abdominal binder improves lung volumes and voice in people with tetraplegic spinal cord injury. Arch Phys Med Rehabil 93: 2189-2197, 2012.

21. Darouiche RO, Al Mohajer M, Siddiq DM and Minard CG: Short versus long course of antibiotics for catheter-associated urinary tract infections in patients with spinal cord injury: A randomized controlled noninferiority trial. Arch Phys Med Rehabil 95: 290-296, 2014.

22. Liu Y, Li X, Zhu S, Zhang JG, Yang M, Qin Q, Deng SC, Wang B, Tian K, Liu L, et al: Ectopic expression of miR-494 inhibited the proliferation, invasion and chemoresistance of pancreatic cancer by regulating SIRT1 and c-Myc. Gene Ther 22: 729-738, 2015.

23. Kim Y, Jo SH, Kim WH and Kweon OK: Antioxidant and anti-inflammatory effects of intravenously injected adipose derived mesenchymal stem cells in dogs with acute spinal cord injury. Stem Cell Res Ther 6: 229, 2015

24. Comegna M, Succoio M, Napolitano M, Vitale M, D'Ambrosio C, Scaloni A, Passaro F, Zambrano N, Cimino F and Faraonio R: Identification of miR-494 direct targets involved in senescence of human diploid fibroblasts. FASEB J 28: 3720-3733, 2014.

(i) (2) This work is licensed under a Creative Commons Attribution-NonCommercial-NoDerivatives 4.0 International (CC BY-NC-ND 4.0) License. 